\title{
L'ensilage des racines de manioc
}

\author{
par H. SERRES $\left(^{*}\right)$ et J. P. TILLON $\left(^{*}\right)$
}

Le manioc est un excellent aliment énergétique pour le bétail. Mais après son arrachage, il se détériore rapidement par hydrolyse de l'amidon et début de fermentation qui lui donne une odeur alcoolique. Les moisissures compliquent rapidement ce processus. Passé trois jours, en climat chaud, il devient inutilisable. En outre, l'arrachage n'est pas réalisable en saison des pluies.

Une solution très généralement utilisée est le séchage au solejl des racines coupées en rondelles ou en cossettes. Mais la dessiccation demande de huit à quinze jours suivant la dimension des fragments, et surtout exige un climat parfaitement sec, ce qui n'est pas toujours le cas.

Soit que le climat soit humide, soit qu'une exploitation ait des dimensions trop importantes, il est possible que le séchage ne constitue pas toujours la solution de la mise en réserve du manioc.

Cela nous a amenés à envisager son ensilage. La récolte peut se faire alors au moment où les racines ont le maximum d'amidon, en saison sèche.

Dans les essais que nous avons réalisés, les racines ont été débarrassées de la terre par nettoyage grossier à $s \propto$, très facile si la terre

(*) I.E.M.V.T., Région de Recherches vétérinaires et zootechniques de Madagascar, B.P. no 862 , Tananarive. est sèche. Les racines ont été coupées soit en gros fragments au coupe-coupe manuel, soit débitées plus finement au coupe racines. L'ensilage a été fait soit en cuve cylindrique cimentée, soit en tranchée de terre avec feuille plastique, soit en cuve métallique. Les résultats sont rassemblés au tableau $\mathbf{I}$.

Il convient de souligner que nous n'avons employé que des maniocs doux couramment cultivés à Madagascar et qui contiennent dans la majorité des cas moins de $100 \mathrm{mg}$ d'acide cyanhydrique par $\mathrm{kg}$.

\section{DISCUSSION}

$\mathrm{Au}$ vu des analyses, les ensilages sont généralement d'excellente qualité, avec une bonne acidification, un pourcentage d'acides acétique et surtout lactique élevé, tandis que la proportion d'acide butyrique est faible voire nulle.

La distribution aux bovins (ensilage $\mathrm{n}^{\circ} 3$ ), aux porcs et aux bovins (les autres) a révélé une excellente appétibilité et une consommation sans aucun refus pour des quantités de $3 \mathrm{~kg} /$ jour par porc et $5 \mathrm{~kg}$ /jour par bœuf. La distribution prolongée ne s'accompagne d'aucun trouble cliniquement décelable.

Nous concluerons que l'ensilage est une forme de mise en réserve du manioc qui peut présenter un grand intérêt lorsque le séchage pose des problèmes. 
Retour au menu

TABLEAU $N^{\circ} 1$

Ensilage des racines de manioc

\begin{tabular}{|c|c|c|c|c|c|}
\hline & 1 & 2 & 3 & 4 & 5 \\
\hline Date d'ensilage & B Novembre & 29 Octobre & Mai & 25 Juillet & 25 Juillet \\
\hline Date d'ouverture & 25 Janvier & 15 Février & Septembre & S Octobre & 5 Octobre \\
\hline Silo & $\begin{array}{l}\text { Tranchée de terre } \\
+ \text { film plastique }\end{array}$ & $\begin{array}{l}\text { Tranchëe de terre } \\
+ \text { film plastique }\end{array}$ & $\begin{array}{l}\text { Cuve } \\
\text { cimentée }\end{array}$ & $\begin{array}{c}\text { Cuve } \\
\text { mêtallique }\end{array}$ & $\begin{array}{l}\text { Cuve } \\
\text { métallique }\end{array}$ \\
\hline Hachage & Machine & Machlne & Main & Machine & Main \\
\hline Prêlèvement & Surface & Profondeur & Profondeur & Profondeur & Profondeur \\
\hline Four $1.000 \mathrm{~g}$ en 8 & & & & & \\
\hline Matière sèche & 354,2 & 382,7 & 416,6 & 405,7 & 399,8 \\
\hline Matières azotées & 10,0 & 9,3 & 8,3 & 12,3 & 11,0 \\
\hline Matières grasses & 1,7 & 1,6 & 1,4 & 1,7 & 3,4 \\
\hline Cellulose brute & 14,6 & 14,1 & 13,9 & 9,2 & 8,9 \\
\hline Minëraux & 12,7 & 13,7 & 6,4 & 12,5 & 10,4 \\
\hline Calcium & 0,57 & 0,59 & 0,54 & 0,88 & 0,70 \\
\hline Phosphore & 0,26 & 0,28 & 0,16 & 0,45 & 0,45 \\
\hline $\mathrm{pH}$ & 4,0 & 4,0 & 3,72 & 4,3 & 4,0 \\
\hline $\begin{array}{c}\text { Pour } 100 \mathrm{~g} \\
\text { d'ensilage en } \mathrm{g}\end{array}$ & & & & & \\
\hline Acldité brute & 0,772 & 0,872 & 0,581 & 0,632 & 0,657 \\
\hline $\begin{array}{c}\text { Ac1dité volatile } \\
\text { totale }\end{array}$ & 0,358 & 0,250 & 0.196 & 0,784 & 0,368 \\
\hline Aclddtê acêtique & 0,301 & 0,286 & 0,194 & 0,806 & 0,454 \\
\hline Aciditê butyriqque & 0,087 & 0,000 & 0,017 & 0,078 & 0,027 \\
\hline Aciditē lactique & 0,900 & 1,039 & 0,892 & 0,584 & 1,067 \\
\hline$\frac{N \text { ammoniacal }}{N \text { total }}$ & $14 \mathrm{p} \cdot 100$ & $20 \mathrm{p} \cdot 100$ & $13 \mathrm{p} \cdot 100$ & $40 \mathrm{p} \cdot 100$ & $20 \mathrm{p} .100$ \\
\hline Apprĕciation & Bon ensilage & Bon ensilage & Bon ensilage & $\begin{array}{l}\text { Assez bon } \\
\text { ensilage }\end{array}$ & Bon ensilage \\
\hline
\end{tabular}

